\title{
Potential Nutrition Support for Age-Related Muscular Conditions
}

\author{
Hua Kern ${ }^{1 *}$, Szabolcs Péter ${ }^{2}$, Manfred Eggersdorfer ${ }^{3}$, Susan Hazels Mitmesser ${ }^{4}$ \\ ${ }^{1,4}$ Nature's Bounty Co., Ronkonkoma NY, USA \\ 2,3 DSM Nutritional Products, Basel, Switzerland
}

Received: March 15, 2018; Accepted: April 18, 2018; Published: May 03, 2018

*Corresponding author: Hua Kern, 2100 Smithtown Avenue, Ronkonkoma NY 11779, USA, Tel: 631-200-3460; E-mail: carinakern@nbty.com

\begin{abstract}
The world's population is aging and the elderly population is living longer. This demographic change poses a challenge to public health: How can the elderly sustain health and well-being? Retention of muscle health can help older adults to preserve independence and improve their quality of life. However, there are limited data on nutrition improvement as an approach to manage age-associated loss of muscle mass and strength, also known as sarcopenia. It is unclear whether specific nutrients could be beneficial to muscle health in the ageing process. To help answer this question, we reviewed the emerging data from human Randomized Controlled Trials (RCTs) on individual nutrients and muscle health in the past decade. Nineteen RCTs reported benefits of the following nutrients, supplemented alone or in combination, on improving muscle mass or strength in the elderly: Proteins and essential amino acids, vitamin D, bovine colostrum, omega-3 fatty acids, and anti-inflammatory ingredients. Cocktail supplementation of multiple nutrients was reported to be more effective than single nutrient interventions. A systems approach integrating multi-faceted interventions may help us better understand the multifactorial etiology of sarcopenia and find effective solutions towards healthy muscle conditions with age.
\end{abstract} Aging

Keywords: Nutrients; Sarcopenia; Muscle mass; Muscle function;

\section{Introduction}

The world's population is aging. By the year 2050, 21\% of the world's population, or 2 billion people, is projected to be $\geq 60$ years of age. Individuals aged $\geq 80$ years are estimated to triple to 392 million [1]. The elderly population is living longer and this demographic change poses a challenge to public health: How can the elderly sustain good health and the highest quality of life? Mobility is an essential component of life quality, which includes muscle, joint and bone maintenance. Extensive research has been conducted on nutrients that influence age-related joint and bone deteriorations. However, there are limited data on nutritional approaches to manage loss of muscle mass and strength with age, also known as sarcopenia. It is estimated that muscle mass and strength start to decline at an annual rate of $1 \%-2 \%$ after the age of 50 years. After 60 years, losses in muscle mass and strength often accelerate to a higher rate, $3 \%$ per year $[2,3]$. Retention of muscle mass and/or strength can help older adults to preserve independence and improve the quality of life $[1,4,5]$.

Currently there is no consensus definition of sarcopenia. The most commonly used criteria to diagnose sarcopenia are from the European Working Group on Sarcopenia in Older People (EWGSOP), the International Working Group on Sarcopenia (IWGS) and Foundation for the National Institutes of Health Sarcopenia Project (FNIH). These three groups define sarcopenia as the presence of both low muscle mass (whole-body or appendicular) and low muscle function (either strength and/ or physical functioning), resulting from an increase in protein catabolism and anabolic resistance [6-8]. However, measures of muscle mass and function are not standardized and arbitrary cut-off values and various interpretations have been applied in clinical trials. Such methodological inconsistencies have led to discrepancies in relevant literature including, but not limited to, prevalence, risk factors and efficacy of interventions.

The etiology of age-related deterioration of muscle mass or strength is yet to be fully understood. Lifestyle factors, such as reduced physical activity and an unbalanced diet, are believed to be one of the main contributors to sarcopenia. Exercise is one known factor that prevents loss of muscle mass and function. A combination of resistance and aerobic exercise with moderate intensity (20 minutes daily, 5 times per week) was reported to increase muscle strength by $38 \%$ and lower the serum concentration of a generic inflammation marker, C-Reactive Protein (CRP) $(\mathrm{P}<0.01)$ [9]. A systematic review of 62 Progressive Resistance Training (PRT) trials (3,674 subjects) reported that PRT was effective in improving muscle strength and some aspects of functional limitations, such as gait speed, among the 
elderly aged 60+ years [10]. A recent review confirmed most exercise interventions improved muscle strength or physical performance, but not always muscle mass among older people [11]. Furthermore, risks associated with exercise could not be evaluated due to lack of data on adverse events [10]. Beneficial effects of exercise training alone may not be enough to improve physical functioning or muscle mass in elderly at risk for, or with sarcopenia [11,12], suggesting a need for multifactorial interventions to achieve clinically relevant results.

The relationship between dietary patterns and sarcopenia has been examined in diverse populations. Cross-sectional data have reported high prevalence of sarcopenia is associated with alcohol intake, low dietary diversity, and insufficient intakes of fruit, vegetables and dairy food [3,13-15]. In particular, high adherence to a Mediterranean diet is associated with slower decline in muscle and physical functioning and a lower risk of sarcopenia among the elderly [16-18]. Unfortunately, these findings are largely based on observational data and there are limited welldesigned Randomized Controlled Trials (RCTs) investigating the efficacy of nutrition interventions on age-related muscular conditions [11]. To help better understand potential nutrition solutions to age-related loss of muscle mass and/or strength, we reviewed the emerging human data from RCTs in the past decade and summarized the evidence supporting nutrition interventions in managing sarcopenic conditions.

\section{Literature Search Methods}

We searched PubMed from January 1, 2007 to June 6, 2017, by using a combination of the following keywords: "nutrient" OR "vitamin" OR "mineral" OR "nutraceutical" AND "mobility" OR "muscle" AND "2007/01/01 to current" [Date-Completion] AND "randomized controlled trial" [Publication Type]. Key words were searched in the title/abstract of articles. Once the search was implemented and the publication titles were retrieved, titles of articles were screened, and abstracts of titles determined to be potentially relevant were retrieved for screening. Then full-text articles of abstracts determined to be potentially relevant were retrieved and reviewed for inclusion or exclusion.

The focus of this review is human RCTs on individual nutrients which are published in English and show improvement in muscle mass or function among older adults. Specific dietary patterns, food groups, gene/drug-nutrient interactions, biochemical/ molecular mechanism, observational and in-vitro studies are not the focus of the present review.

Table 1 summarizes nineteen human RCTs that were published in English and reported positive effects of individual nutrients on age-related loss of muscle mass or function. In the section of "Literature Summary and Discussion", we cite additional studies, reviews and meta-analyses in order to provide a balanced point of view beyond the RCTs that are listed in Table 1.

\section{Literature Summary and Discussion}

Nineteen RCTs reported benefits of the following nutrients, either supplemented alone or with other nutrients, for improving the deterioration of muscle mass or strength due to ageing: Proteins and Essential Amino Acids (EAAs), vitamin D, bovine colostrum, omega-3 fatty acids, and select anti-inflammatory ingredients (curcumin, combination of multiple compounds). In these human trials, study populations were from North America, South America, Europe and Asia with a mean age of $\geq 55-65$ years, and the duration of nutrition interventions ranged from 28 days to one year. Table 1 summarizes key characteristics of these RCTs including objectives, nutrition interventions, main outcomes and key findings.

\section{Proteins and EAAs}

Protein supplementation has been reported to have beneficial effects on muscle mass and strength among healthy adults, including the elderly. A higher protein intake than the recommended dietary allowance of $0.8 \mathrm{~g} / \mathrm{kg}$ body weight (BW)/day may help preserve muscle mass and support healthy aging besides physical activity $[19,20]$. A meta-analysis of 22 randomized trials reported protein supplementation at a dose of $>1.2 \mathrm{~g} / \mathrm{kg} \mathrm{BW} /$ day during resistance exercise training increased Fat-Free Mass (FFM) by an average of $0.69 \mathrm{~kg}$ and leg strength among healthy adults aged 12-72 years compared to placebo $(p<0.005)$ [20]. Subgroup analysis of six studies conducted in older subjects ( $>50$ years of age) indicated an increase of $38 \%$ in FFM and a gain of 33\% in muscle strength with protein supplementation [20]. These benefits were observed for protein supplementation either as supplements or through food. However, it remains unknown if such benefits could be generalized to those with sarcopenia. In a recent trial, $210 \mathrm{~g}$ of ricotta cheese $(18 \mathrm{~g}$ protein) was consumed daily along with the habitual diet among Mexican older adults without sarcopenia [21]. Based on local reference intake of dietary protein $(0.9 \mathrm{~g} / \mathrm{kg} \mathrm{BW} /$ day $)$ in older people, the addition of ricotta cheese was estimated to increase protein intake in the intervention group from $0.9 \mathrm{~g} / \mathrm{kg} \mathrm{BW} /$ day to $1.2 \mathrm{~g} / \mathrm{kg} \mathrm{BW} /$ day for the 12 -week duration of the study [21]. It was likely that increase in protein intake via ricotta cheese contributed to improved muscle mass in the intervention group compared to placebo [21]. In particular, at 12 weeks, the mean value of appendicular muscle mass in the intervention group was significantly increased by $0.6 \mathrm{~kg}$ [Standard Deviation (SD): $\pm 3.5 \mathrm{~g}$, while the change from baseline values was negative in the control group (mean $\pm \mathrm{SD}:-1 \pm 2.6 \mathrm{~g}$ ) [21]. In contrast, the same intervention was implemented among Mexican elderly with sarcopenia but did not improve any of the outcome measures [22]. More research is needed to help understand if responsiveness to protein supplementation among the elderly is influenced by muscle status (i.e. healthy, at risk, or sarcopenic).

Supplementation of EAAs alone has limited or no benefit on muscle mass and function even at a high dose (i.e. $6 \mathrm{~g}$ EAAs/day for 3 months) [23]. When supplemented with other nutrients, favorable effects of EAAs have been reported in a number of trials. A systematic review reported EAAs in combination with 2.5-2.8 g leucine were beneficial to muscle mass and function [12]. Favorable effects with a smaller dose of leucine (1.2 g/day) 


\begin{tabular}{|c|c|c|c|c|c|c|c|c|}
\hline Reference & Design & Objectives & $\begin{array}{c}\text { Nutrient } \\
\text { Intervention }\end{array}$ & $\begin{array}{l}\text { Main Health } \\
\text { Outcomes }\end{array}$ & Population & Sample Size & Key Findings & Additional Notes \\
\hline $\begin{array}{c}\text { Da Boit } \\
2017 \text { [38] }\end{array}$ & $\begin{array}{l}\text { Randomized, } \\
\text { placebo- } \\
\text { controlled, } \\
\text { double-blind } \\
\text { trial (placebo } \\
\text { versus } \\
\text { intervention) }\end{array}$ & $\begin{array}{l}\text { To evaluate gender } \\
\text { differences in the } \\
\text { effects of fish oil } \\
\text { supplementation } \\
\text { together with } \\
\text { resistance exercise } \\
\text { on muscle mass and } \\
\text { function among the } \\
\text { elderly. }\end{array}$ & $\begin{array}{c}18 \text { weeks, } \\
\text {-Intervention: } \\
\text { resistance training } \\
\text { (twice per week) } \\
+3 \mathrm{~g} / \text { day omega-3 } \\
\text { (providing } 2.1 \mathrm{~g} \mathrm{EPA} \\
+0.6 \mathrm{~g} \mathrm{DHA} / \text { day) } \\
\text {-Placebo: resistance } \\
\text { training (twice per } \\
\text { week) + identical- } \\
\text { looking placebo (3 } \\
\text { g/day safflower oil) }\end{array}$ & $\begin{array}{l}\text { Muscle function } \\
\text { (knee-extensor } \\
\text { isometric and } \\
\text { isokinetic } \\
\text { torque), physical } \\
\text { performance } \\
\text { (short-performance } \\
\text { physical battery } \\
\text { test) }\end{array}$ & $\begin{array}{c}\text { Older adults } \\
\text { aged }>60 \text { years } \\
\text { UK }\end{array}$ & $\begin{array}{c}\mathrm{N}=50 \\
\text {-Placebo: } \mathrm{n}=23 \\
\text {-Intervention: } \\
\mathrm{n}=27\end{array}$ & $\begin{array}{l}\text { At the end of } \\
\text { intervention, } \\
\text { supplemented } \\
\text { women, not } \\
\text { men, had greater } \\
\text { increases in } \\
\text { resistance } \\
\text { training-induced } \\
\text { muscle isometric } \\
\text { torque and muscle } \\
\text { quality than the } \\
\text { placebo group } \\
(\mathrm{P}<0.05) .\end{array}$ & $\begin{array}{l}\text { No differences in markers of } \\
\text { inflammation (TNF- } \alpha \text {, IL-6) were } \\
\text { observed between intervention } \\
\text { and placebo groups. }\end{array}$ \\
\hline $\begin{array}{c}\text { Abe } 2016 \\
{[24]}\end{array}$ & $\begin{array}{l}\text { Randomized, } \\
\text { controlled, } \\
\text { single-blind, } \\
\text { parallel group } \\
\text { trial (control } \\
\text { versus two } \\
\text { interventions ) }\end{array}$ & $\begin{array}{c}\text { To evaluate a } \\
\text { combination of } \\
\text { nutrients [L-leucine } \\
\text { and } \mathrm{D}_{3} \text { - enriched } \\
\text { essential amino } \\
\text { acids (LD-EAAs) } \\
\text { +medium-chain } \\
\text { triglycerides } \\
\text { (MCT), or , LD- } \\
\text { EAAs + long-chain } \\
\text { triglycerides (LCT)] } \\
\text { in habitual diets for } \\
\text { the treatment of } \\
\text { sarcopenia in the } \\
\text { elderly }\end{array}$ & $\begin{array}{l}3 \text { months (1 time/ } \\
\text { day at dinner): } \\
\text {-LD-EAAs + MCT } \\
\text { group: L-leucine } \\
\text { (1.2 g) enriched } \\
\text { EAAs ( } 40 \% \text { leucine } \\
\text { in 3g EAAs) + D3 } \\
\text { (800 IU) + MCT } 6 \text { g). } \\
\text {-LD-EAAs + LCT } \\
\text { group: } \\
\text { L-leucine (1.2 g) } \\
\text { enriched EAAs } \\
\text { (40\% leucine in 3g } \\
\text { EAAs) + D3 (800 IU) } \\
\text { + LCT (6 g). } \\
\text {-Control: no } \\
\text { supplement }\end{array}$ & $\begin{array}{l}\text { At baseline and } \\
\text { after the 3-month } \\
\text { intervention: } \\
\text { Muscle strength } \\
\text { (right-hand grip } \\
\text { strength), function } \\
\text { (walking speed, } \\
\text { respiratory } \\
\text { function), } \\
\text { appendicular } \\
\text { muscle mass (mid- } \\
\text { upper arm muscle } \\
\text { area) , cognitive } \\
\text { function }\end{array}$ & $\begin{array}{c}\text { Elderly nursing } \\
\text { home residents } \geq \\
65 \text { years (mean } \\
\text { age: } 86.6 \text { years). } \\
\text { Yokohama, } \\
\text { Japan }\end{array}$ & $\begin{array}{c}\mathrm{N}=36 \\
\text {-Control: } \mathrm{n}=11 \\
\text {-LD+MCT: } \mathrm{n}=13 \\
\text {-LD+LCT: } \mathrm{n}=12\end{array}$ & 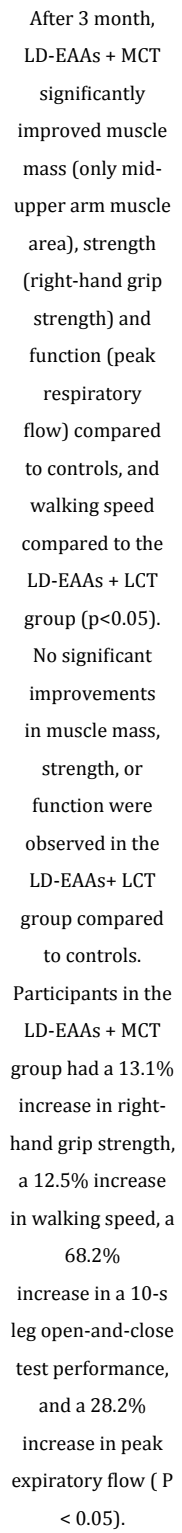 & $\begin{array}{l}\text { Data collection: } \\
\text { September - December } 2014 . \\
\text { Two intervention groups } \\
\text { received energy-matched } \\
\text { supplementation. The control } \\
\text { group did not receive an energy- } \\
\text { equivalent placebo per the study } \\
\text { design. } \\
\text { Food records were collected } \\
\text { daily; no difference between } \\
\text { groups at baseline and the end } \\
\text { of intervention was found. } \\
\text { Exercise protocols that were } \\
\text { conducted in the nursing home } \\
\text { remained unchanged through the } \\
\text { intervention period. } \\
\text { Subjects were not blinded about } \\
\text { if they received supplements } \\
\text { or not, but they were blinded } \\
\text { about which supplements they } \\
\text { received. Examiners who oversaw } \\
\text { the walking speed test were } \\
\text { blinded about the intervention } \\
\text { groups, but examiners for other } \\
\text { assessment were aware of the } \\
\text { group assignment. } \\
\text { Compliance with } \\
\text { supplementation: } 100 \% \text {. No } \\
\text { side effects were reported. } \\
\text { Limitations: muscle mass was } \\
\text { measured by an anthropometric } \\
\text { analysis, not directly measured } \\
\text { group receiving MCTs only so the } \\
\text { eff of MCTs alone could not } \\
\text { be There was not a }\end{array}$ \\
\hline
\end{tabular}




\begin{tabular}{|c|c|c|c|c|c|c|c|c|}
\hline $\begin{array}{c}\text { Franceschi } \\
2016[43]\end{array}$ & $\begin{array}{c}\text { Parallel- } \\
\text { group clinical } \\
\text { trial (control } \\
\text { versus two } \\
\text { interventions) }\end{array}$ & $\begin{array}{l}\text { To evaluate effects } \\
\text { of curcumin } \\
\text { (Meriva } ® \text { ) } \\
\text { supplementation } \\
\text { as an addition to } \\
\text { a standardized } \\
\text { diet and exercise } \\
\text { on parameters of } \\
\text { sarcopenia }\end{array}$ & $\begin{array}{c}\text { 3 months: } \\
\text {-Standard } \\
\text { management } \\
\text { group: exercise } \\
\text { + balanced diet } \\
\text { including proteins } \\
\text { - Standard } \\
\text { management } \\
\text { + Meriva }{ }^{\circledR}(1 \mathrm{~g} \\
\text { curcumin/tablet, } 1 \\
\text { tablet/day) } \\
\text {-Standard } \\
\text { management } \\
\text { + Meriva }{ }^{\circledR}(1 \\
\text { g curcumin/ } \\
\text { tablet, } 1 \text { tablet/ } \\
\text { day) + additional } \\
\text { supplementation (D } \\
800 \text { IU/day, C } 500 \\
\text { mg/day, isoleucine } \\
3 \mathrm{~g} / \text { day, carnitine } 1 \\
\text { g/day) }\end{array}$ & $\begin{array}{l}\text { At baseline and } \\
\text { after the 3-month } \\
\text { intervention: Muscle } \\
\text { strength (hand } \\
\text { grip, weight lifting), } \\
\text { physical function } \\
\text { ( time/distance of } \\
\text { feeling tired after } \\
\text { cycling, walking and } \\
\text { climbing stairs), } \\
\text { other measures (i.e. } \\
\text { oxidative stress) }\end{array}$ & $\begin{array}{c}\text { Otherwise } \\
\text { healthy elderly } \\
\text { aged } \geq 65 \text { years } \\
\text { (mean age: } \sim 73 \\
\text { years) who } \\
\text { complained for } \\
\text { strength loss } \\
\text { and physical } \\
\text { tiredness. } \\
\text { Genoa, Italy. }\end{array}$ & $\begin{array}{c}\mathrm{N}=86 \\
\text {-Standard } \\
\text { management: } \mathrm{n}=33 \\
\text {-Standard } \\
\text { management + } \\
\text { Meriva: } \mathrm{n}=31 \\
\text {-Standard } \\
\text { management } \\
\text { + Meriva + } \\
\text { additional } \\
\text { supplementation: } \\
\mathrm{n}=22\end{array}$ & $\begin{array}{c}\text { Significant } \\
\text { improvements } \\
\text { in all parameters } \\
\text { were observed } \\
\text { in the two } \\
\text { supplementation } \\
\text { groups (p<0.05), } \\
\text { but not in } \\
\text { the standard } \\
\text { management } \\
\text { group. } \\
\text { Compared to } \\
\text { the standard } \\
\text { management } \\
\text { group, both } \\
\text { supplementation } \\
\text { groups had } \\
\text { significant } \\
\text { improvements } \\
\text { in all parameters } \\
\text { (p<0.05). }\end{array}$ & $\begin{array}{l}\text { Meriva has a novel phospholipid } \\
\text { delivery system of curcumin } \\
\text { (named phytosome }{ }^{\circledast 10} \text { ) to } \\
\text { overcome the poor systemic } \\
\text { bioavailability of curcumin. } \\
\text { Good compliance to } \\
\text { supplementation ( }>95 \% \text { ). } \\
\text { Observed benefits may be } \\
\text { partly due to anti-inflammatory } \\
\text { properties of curcumin. }\end{array}$ \\
\hline $\begin{array}{c}\text { Rondanelli } \\
2016 \text { [12] }\end{array}$ & $\begin{array}{l}\text { Randomized, } \\
\text { placebo- } \\
\text { controlled, } \\
\text { double-blind, } \\
\text { parallel-group } \\
\text { superiority } \\
\text { clinical trial } \\
\text { (placebo } \\
\text { versus } \\
\text { intervention) }\end{array}$ & $\begin{array}{l}\text { To assess the } \\
\text { efficacy of } \\
\text { nutritional } \\
\text { supplementation } \\
\text { (whey protein } \\
+ \text { EAAs + } \mathrm{D}_{3} \text { ) } \\
\text { concurrent } \\
\text { with regular } \\
\text { physical activity } \\
\text { in improving fat- } \\
\text { free mass, muscle } \\
\text { strength and } \\
\text { physical function } \\
\text { and quality of life }\end{array}$ & $\begin{array}{l}12 \text { weeks ( } 1 \text { time/ } \\
\text { day with meals): } \\
\text { Whey protein }(22 \\
\text { g), EAAs (10.9 } \\
\text { g, including } 4 \mathrm{~g} \\
\text { leucine), vitamin } \\
\text { D3 [2.5 } \mu \mathrm{g}(100 \mathrm{IU})] \text {, } \\
\text { Concurrent regular } \\
\text { physical activity. }\end{array}$ & $\begin{array}{l}\text { At baseline and } \\
\text { after the } 12 \text {-week } \\
\text { intervention: Fat- } \\
\text { free mass (FFM), } \\
\text { muscle strength, } \\
\text { physical function, } \\
\text { quality of life. }\end{array}$ & $\begin{array}{c}\text { Elderly } \\
\text { sarcopenic } \\
\text { patients aged } \geq \\
65 \text { years (mean } \\
\text { age: } 80.3 \text { years), } \\
\text { Pavia, Italy }\end{array}$ & $\begin{array}{c}\mathrm{N}=130 \\
\text {-Placebo: } \mathrm{n}=69 \\
\text {-Intervention: } \\
\mathrm{n}=61\end{array}$ & $\begin{array}{l}\text { Compared with } \\
\text { placebo (exercise } \\
\text { training only), } \\
\text { nutritional } \\
\text { supplementation } \\
\text { plus exercise } \\
\text { training increased } \\
\text { FFM by } 1.7 \\
\text { kg, relative } \\
\text { skeletal muscle } \\
\text { mass (RSMM), } \\
\text { handgrip strength, } \\
\text { physical function, } \\
\text { nutritional status } \\
\text { and insulin-like } \\
\text { growth factor I } \\
\text { (IGF-I) (P<0.01), } \\
\text { and reduced } \\
\text { inflammation } \\
\text { (C-reactive } \\
\text { protein, CRP) } \\
\text { "68\% of sarcopenic } \\
\text { people became } \\
\text { nonsarcopenic." }\end{array}$ & $\begin{array}{l}\text { Data collection: Jan 2013-Jun } \\
2014 . \\
\text { Sarcopenia definition: RSMM < } \\
7.26 \mathrm{~kg} / \mathrm{m} 2 \text { for men, }<5.5 \mathrm{~kg} / \mathrm{m} 2 \\
\text { for women. } \\
\text { Dietary supplements included } \\
\text { other nutrients (carbohydrates, } \\
\text { fiber, calcium, phosphorus, } \\
\text { sodium, magnesium, iron) } \\
\text { Participants received a control } \\
\text { diet providing a mean of } 300 \\
\text { IU of vitamin D daily. All } \\
\text { subjects engaged in a controlled } \\
\text { physical activity program } \\
\text { (moderate intensity, resistance+ } \\
\text { aerobic, } 20 \text { minutes daily, } 5 \\
\text { times/week for } 12 \text { weeks). } \\
\text { Nutritional assessment included } \\
\text { anthropometry, diet, and general } \\
\text { (lifestyle, medication, and } \\
\text { mobility) Compliance: } 100 \% \\
\text { Supplement was well tolerated. } \\
\text { Limitations: blood vitamin } \\
\text { D concentrations were not } \\
\text { assessed. Effects of vitamin D } \\
\text { were not separated from essential } \\
\text { amino acids. }\end{array}$ \\
\hline
\end{tabular}









\begin{tabular}{|c|c|c|c|c|c|c|c|c|}
\hline $\begin{array}{l}\text { Verreijen } \\
2015 \text { [26] }\end{array}$ & $\begin{array}{c}\text { Randomized, } \\
\text { placebo- } \\
\text { controlled, } \\
\text { double-blind, } \\
\text { parallel-group } \\
\text { trial (placebo } \\
\text { versus } \\
\text { intervention) }\end{array}$ & $\begin{array}{l}\text { To examine } \\
\text { the effects of } \\
\text { a supplement } \\
\text { (whey protein } \\
\text { + leucine }+\mathrm{D}_{3}+ \\
\text { other nutrients) on } \\
\text { muscle mass and } \\
\text { strength during a } \\
\text { 13-week weight- } \\
\text { loss program (a } \\
\text { hypocaloric diet + } \\
\text { resistance exercise } \\
\text { training) in obese } \\
\text { older adults. }\end{array}$ & $\begin{array}{c}13 \text { weeks [10 } \\
\text { servings/week, } \\
\text { including } 1 \\
\text { serving daily } \\
\text { before breakfast } \\
\text { and } 3 \text { servings } \\
\text { immediately after } \\
\text { exercise training } \\
\text { (3 times/wk)] } \\
\text {-Intervention (per } \\
\text { serving, } 150 \text { kcal): } \\
\text { whey protein } \\
\text { (20.7g), leucine } \\
\text { (2.8g), D3 (800 IU), } \\
\text { other nutrients (9g } \\
\text { carbohydrate, 1.3g } \\
\text { soluble fiber, fat, } \\
\text { minerals-sodium, } \\
\text { potassium, chloride) } \\
\text { - Placebo (per } \\
\text { serving, } 150 \text { kcal): } \\
\text { an isocaloric } \\
\text { control product } \\
\text { (carbohydrates, fats, } \\
\text { minerals-sodium, } \\
\text { potassium, chloride) }\end{array}$ & $\begin{array}{c}\text { At baseline } \\
\text { and week } 13 \text { of } \\
\text { intervention: } \\
\text { Body composition } \\
\text { including } \\
\text { appendicular } \\
\text { muscle mass (by } \\
\text { DXA) } \\
\text { At baseline, } \\
\text { week } 7 \text { and } 13 \text { of } \\
\text { intervention: Body } \\
\text { weight/BMI/waist } \\
\text { circumference, } \\
\text { handgrip } \\
\text { strength, physical } \\
\text { performance } \\
\text { (walking, gait speed, } \\
\text { and chair stand } \\
\text { tests) }\end{array}$ & $\begin{array}{c}\text { Obese older } \\
\text { adults aged } \geq 55 \\
\text { years (mean age } \\
\text { at enrollment: } \\
63 y \text {; mean } \\
\text { BMI: } 33 \mathrm{~kg} / \mathrm{m}^{2} \text { ) } \\
\text { Amsterdam, } \\
\text { Netherlands }\end{array}$ & $\begin{array}{c}\mathrm{N}=60 \\
\text { Placebo: } \mathrm{n}=30 \\
\text { Intervention: } \\
\mathrm{n}=30\end{array}$ & $\begin{array}{l}\text { The } 13 \text {-week } \\
\text { changes in } \\
\text { appendicular and } \\
\text { leg muscle mass } \\
\text { were different } \\
\text { between two } \\
\text { groups (p<0.05): } \\
\text { Change in } \\
\text { appendicular } \\
\text { muscle mass: } \\
\text { Intervention vs } \\
\text { Placebo: } \\
0.4 \pm 1.2 \mathrm{~kg} \text { vs } \\
-0.5 \pm 2.1 \mathrm{~kg} \\
\text { Change in leg } \\
\text { muscle mass: } \\
\text { Intervention vs } \\
\text { Placebo: } \\
0.3 \pm 1.2 \mathrm{~kg} \text { vs } \\
-0.6 \pm 1.8 \mathrm{~kg} \\
\text { No difference in } \\
\text { improvements of } \\
\text { muscle strength } \\
\text { and function } \\
\text { between groups. } \\
\text { Both groups lost } \\
\text { body weight and } \\
\text { fat mass without } \\
\text { differences } \\
\text { between groups } \\
\text { (p>0.05) }\end{array}$ & $\begin{array}{l}\text { Data collection: March } 2011 \text { - } \\
\text { June } 2012 . \\
\text { Obesity definition: BMI }>30 \text { or } \\
>28 \text { with waist circumference } \\
>88 \mathrm{~cm} \text { (women) or }>102 \mathrm{~cm} \\
\text { (men) } \\
\text { All subjects were on a hypocaloric } \\
\text { diet (600 kcal below Dutch } \\
\text { estimated energy needs) and } \\
\text { participated in a resistance } \\
\text { exercise program (3 times/week } \\
\text { for } 1 \text { h) throughout the 13-wk } \\
\text { intervention period. } \\
\text { Compliance (consumption of } \\
\text { at least } 7 \text { products/week): no } \\
\text { difference between groups } \\
\text { (intervention versus placebo: } \\
91 \% \text { versus } 97 \% \text { ) } \\
\text { Limitation: } \\
\text { High loss to follow-up for the } \\
\text { primary outcome (25\%) }\end{array}$ \\
\hline $\begin{array}{c}\text { Smith } 2015 \\
\text { [39] }\end{array}$ & $\begin{array}{c}\text { Randomized, } \\
\text { placebo- } \\
\text { controlled, } \\
\text { double-blind, } \\
\text { parallel-group } \\
\text { trial (placebo } \\
\text { versus } \\
\text { intervention) }\end{array}$ & $\begin{array}{c}\text { To test if } \\
\text { supplementation of } \\
\text { omega-3 fatty acids } \\
\text { for } 6 \text { months would } \\
\text { increase muscle } \\
\text { mass and function } \\
\text { in older adults }\end{array}$ & $\begin{array}{c}6 \text { months, } \\
\text { Intervention: omega } \\
3 \text { supplement } \\
\text { (Lovaza, } \\
\text { GlaxoSmithKline) } \\
\text { providing a daily } \\
\text { intake of } 1.86 \mathrm{~g} \\
\text { EPA + } 1.50 \mathrm{~g} \mathrm{DHA} \\
\text { Placebo: identical } \\
\text { looking pills } \\
\text { containing corn oil }\end{array}$ & $\begin{array}{l}\text { At baseline and } \\
6 \text { months of } \\
\text { intervention: Thigh } \\
\text { muscle volume } \\
\text { (by MRI), muscle } \\
\text { strength including } \\
\text { handgrip strength } \\
\text { and 1-RM muscle } \\
\text { strength (leg \& } \\
\text { chest press, knee } \\
\text { extension \& flexion) }\end{array}$ & $\begin{array}{c}\text { Healthy older } \\
\text { adults aged 60- } \\
85 \text { years } \\
\text { St Louis, MO }\end{array}$ & $\begin{array}{c}\mathrm{N}=44 \\
\text { Placebo: } \mathrm{n}=15 \\
\text { Intervention: } \mathrm{n}=29\end{array}$ & $\begin{array}{c}\text { Compared with } \\
\text { the placebo } \\
\text { group, omega-3 } \\
\text { supplementation } \\
\text { for } 6 \text { months } \\
\text { improved thigh } \\
\text { muscle volume } \\
\text { by } 3.6 \% \text { (p<0.05), } \\
\text { average isokinetic } \\
\text { muscle power by } \\
5.6 \% \text { (p<0.10), } \\
\text { handgrip strength } \\
\text { by } 2.3 \mathrm{~kg}(\mathrm{p}<0.05 \text { ), } \\
\text { and 1-RM muscle } \\
\text { strength by } 4.0 \% \\
\text { (p<0.05). }\end{array}$ & $\begin{array}{l}\text { High loss to follow up rate } \\
\text { (27\%). Study target subjects } \\
\text { were } 60 \text { and } 44 \text { completed the } \\
\text { study. Completer-analysis was } \\
\text { employed in this study, not } \\
\text { Intention to Treat analysis. }\end{array}$ \\
\hline
\end{tabular}




\begin{tabular}{|c|c|c|c|c|c|c|c|c|}
\hline $\begin{array}{l}\text { Aleman- } \\
\text { Mateo } \\
2014 \text { [21] }\end{array}$ & $\begin{array}{l}\text { Randomized, } \\
\text { controlled, } \\
\text { single-blind, } \\
\text { parallel- } \\
\text { group trial } \\
\text { (control versus } \\
\text { intervention) }\end{array}$ & $\begin{array}{l}\text { To investigate } \\
\text { whether adding } \\
210 \mathrm{~g} \text { of ricotta } \\
\text { cheese (18 g } \\
\text { protein) daily into } \\
\text { the habitual diet } \\
\text { would improve } \\
\text { appendicular } \\
\text { skeletal muscle } \\
\text { mass (ASMM), } \\
\text { handgrip strength, } \\
\text { and physical } \\
\text { performance in } \\
\text { non-sarcopenic } \\
\text { older subjects. }\end{array}$ & $\begin{array}{c}12 \text { weeks, } \\
\text { Intervention: } \\
\text { habitual diet + } \\
\text { Ricotta cheese } \\
\text { (210 g/day =18 } \\
\text { g protein/day) } \\
\text { Control: habitual } \\
\text { diet only }\end{array}$ & $\begin{array}{c}\text { ASMM (by } \\
\text { DXA), handgrip } \\
\text { strength, physical } \\
\text { performance (by } \\
\text { SPPB) including gait } \\
\text { speed, chair rise } \\
\text { test, balance }\end{array}$ & $\begin{array}{c}\text { Non-sarcopenic } \\
\text { older adults } \geq \\
60 \text { years (mean } \\
\text { age: } 70.2 \text { years) } \\
\text { Mexico }\end{array}$ & $\begin{array}{c}\mathrm{N}=100 \\
\text { Control: } \mathrm{n}=50 \\
\text { Intervention: } \mathrm{n}=50\end{array}$ & $\begin{array}{c}\text { The addition of } \\
210 \mathrm{~g} \text { of ricotta } \\
\text { cheese for } 12 \\
\text { weeks improved } \\
\text { ASMM by 0.6kg } \\
\text { (versus baseline), } \\
\text { which was } \\
\text { significantly } \\
\text { different (p<0.01) } \\
\text { from controls } \\
\text { (week } 12 \text { versus } \\
\text { baseline: }-1 \mathrm{~g} \text { ). } \\
\text { No difference } \\
\text { in changes in } \\
\text { handgrip strength } \\
\text { or physical } \\
\text { performance } \\
\text { between groups } \\
\text { P } \geq 0.05 \text { ). }\end{array}$ & $\begin{array}{l}\text { Sarcopenia definition: a low } \\
\text { relative ASMM below two } \\
\text { standard deviations from the } \\
\text { mean value of the ASMM of a } \\
\text { young Mexican adult population. } \\
\text { The addition of ricotta cheese } \\
\text { was estimated to increase protein } \\
\text { intake from } 0.9 \text { to } 1.2 \mathrm{~g} / \mathrm{kg} \\
\text { BW/day. The same nutritional } \\
\text { intervention protocol was } \\
\text { implemented among sarcopenic } \\
\text { elderly prior to this trial but no } \\
\text { improvement in measures of } \\
\text { sarcopenia including ASMM was } \\
\text { found. }\end{array}$ \\
\hline $\begin{array}{c}\text { Duff } 2014 \\
\text { [35] }\end{array}$ & $\begin{array}{c}\text { Randomized, } \\
\text { placebo- } \\
\text { controlled, } \\
\text { double-blind, } \\
\text { parallel- } \\
\text { group trial } \\
\text { (control versus } \\
\text { intervention) }\end{array}$ & $\begin{array}{l}\text { To compare the } \\
\text { effects of bovine } \\
\text { colostrum vs } \\
\text { whey protein } \\
\text { supplementation } \\
\text { during a resistance } \\
\text { training on muscle } \\
\text { strength, thickness, } \\
\text { body composition } \\
\text { and other } \\
\text { indicators (i.e. } \\
\text { inflammation and } \\
\text { bone resorption) } \\
\text { among older adults } \\
\text { aged } 50+\text { year }\end{array}$ & $\begin{array}{c}8 \text { weeks bovine } \\
\text { colostrum or } \\
\text { whey protein, } \\
\text { Bovine colostrum } \\
\text { intervention: } 60 \mathrm{~g} / \\
\text { day Whey protein } \\
\text { placebo: } 60 \mathrm{~g} / \text { day } \\
\text { (consumed } 3 \text { times/ } \\
\text { day, } 20 \mathrm{~g} / \text { time), } \\
\text { overall nutritional } \\
\text { composition was } \\
\text { matched to bovine } \\
\text { colostrum. }\end{array}$ & $\begin{array}{l}\text { At baseline and } \\
\text { after the 8-week } \\
\text { intervention: } \\
\text { Upper (by bench } \\
\text { press exercise) } \\
\text { and lower (by leg } \\
\text { press test) muscle } \\
\text { strength, muscle } \\
\text { mass (by DXA), } \\
\text { bone resorption (by } \\
\text { urinary cross-linked } \\
\text { N-telopeptides of } \\
\text { Type } 1 \text { collagen, } \\
\text { Ntx), inflammation } \\
\text { (C-reactive protein, } \\
\text { CRP) }\end{array}$ & $\begin{array}{l}\text { Older adults } \\
\text { aged 50+ } \\
\text { years (mean } \\
\text { age: } 59 \text { years) } \\
\text { Saskatoon, } \\
\text { Canada }\end{array}$ & $\begin{array}{c}\mathrm{N}=40 \\
\text { Placebo: } \mathrm{n}=21 \\
\text { Intervention: } \mathrm{n}=19\end{array}$ & $\begin{array}{l}\text { The bovine } \\
\text { colostrum group } \\
\text { had a higher } \\
\text { increase in lower } \\
\text { body strength (by } \\
\text { leg press test) } \\
\text { and a greater } \\
\text { decrease in bone } \\
\text { resorption (by } \\
\text { Ntx) compared to } \\
\text { the whey protein } \\
\text { placebo (p<0.05). } \\
\text { Both groups } \\
\text { had significant } \\
\text { increases in lean } \\
\text { tissue mass, } \\
\text { muscle thickness } \\
\text { (by ultrasound), } \\
\text { upper body } \\
\text { strength (by bench } \\
\text { press exercise) } \\
\text { and bone mineral } \\
\text { content compared } \\
\text { to baseline } \\
\text { values (p<0.05). } \\
\text { No difference in } \\
\text { changes of these } \\
\text { measures between } \\
\text { groups }\end{array}$ & $\begin{array}{l}\text { The mechanism for the greater } \\
\text { increase in leg press strength } \\
\text { in the bovine colostrum group } \\
\text { compared to whey protein is not } \\
\text { clear. More research is needed } \\
\text { to confirm this benefit. No } \\
\text { difference between groups for } \\
\text { changes in systemic inflammation } \\
\text { (CRP). } \\
\text { Long-term effects of bovine } \\
\text { colostrum need to be investigated } \\
\text { further. }\end{array}$ \\
\hline
\end{tabular}




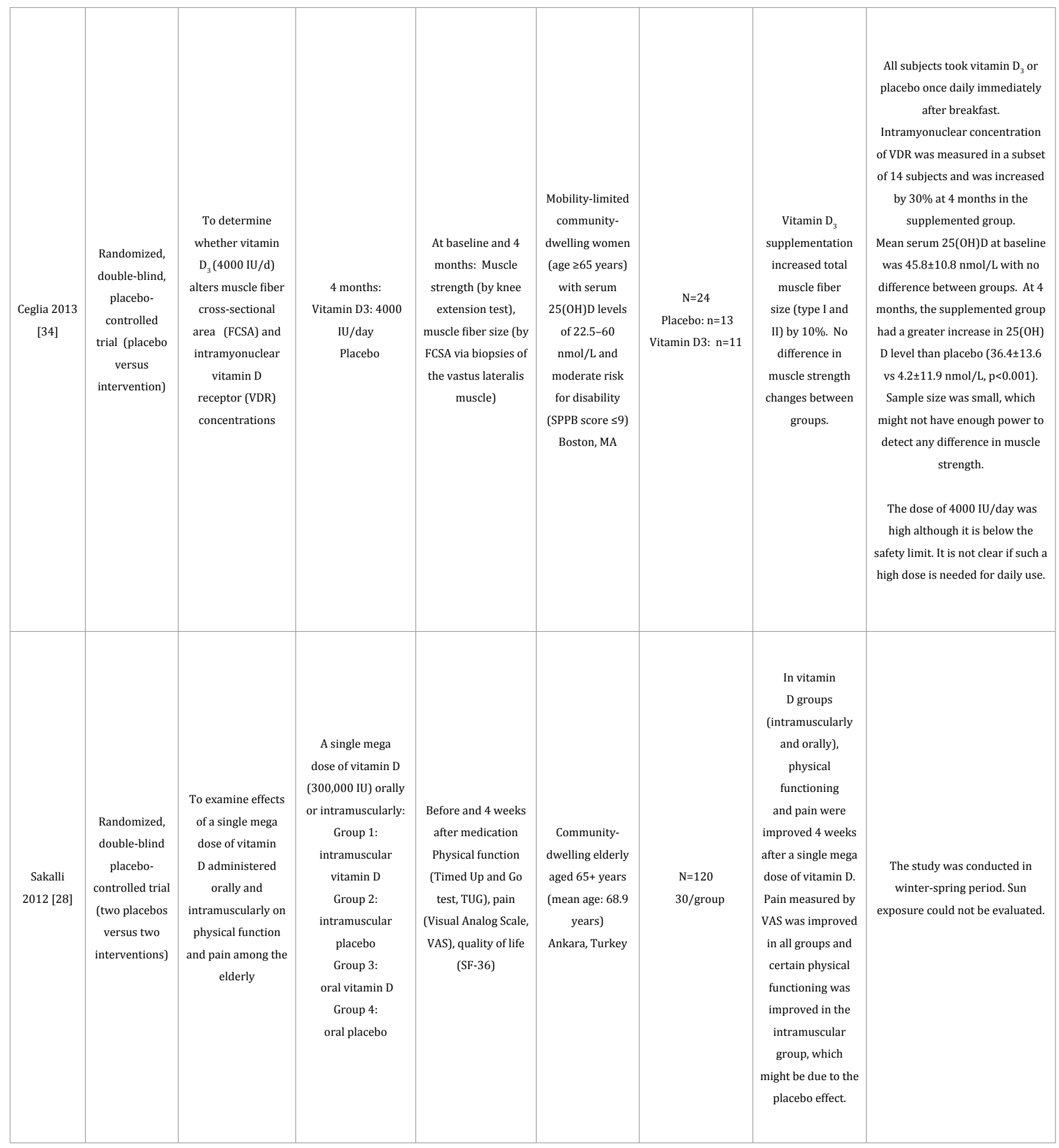




\begin{tabular}{|c|c|c|c|c|c|c|c|c|}
\hline $\begin{array}{l}\text { Rodacki } \\
2012 \text { [37] }\end{array}$ & $\begin{array}{l}\text { Randomized, } \\
\text { controlled trial } \\
\text { (one control } \\
\text { versus two } \\
\text { interventions) }\end{array}$ & $\begin{array}{l}\text { To investigate the } \\
\text { effect of fish oil } \\
\text { supplementation } \\
\text { and strength } \\
\text { training on muscle } \\
\text { strength and } \\
\text { functioning among } \\
\text { elderly women }\end{array}$ & $\begin{array}{c}\text { Daily } \\
\text { supplementation } \\
\text { of fish oil }(2 \mathrm{~g} / \text { day, } \\
\text { providing } \sim 0.4 \mathrm{~g} \\
\text { EPA +0.3 g DHA/ } \\
\text { day): } \\
\text { Control: strength } \\
\text { training only } \\
\text { Intervention } 90 \\
\text { days: fish oil + } \\
\text { strength training } \\
\text { for } 90 \text { days } \\
\text { Intervention } 150 \\
\text { days: fish oil for } \\
60 \text { days prior to } \\
\text { strength training, } \\
\text { then together with } \\
\text { strength training for } \\
90 \text { days }\end{array}$ & $\begin{array}{l}\text { Muscle strength } \\
\text { (i.e. peak torque } \\
\text { by maximal } \\
\text { voluntary isometric } \\
\text { contraction), } \\
\text { functioning (foot } \\
\text { up and go, sit and } \\
\text { reach, chair rising, } \\
\text { 6-min walk) }\end{array}$ & $\begin{array}{l}\text { Healthy white } \\
\text { women aged > } \\
60 \text { years Brazil }\end{array}$ & $\begin{array}{c}\mathrm{N}=45 \quad \text { Control: } \\
\mathrm{n}=15 \\
\text { Intervention } \\
90 \text { days: } \mathrm{n}=15 \\
\text { Intervention } 150 \\
\text { days: } \mathrm{n}=15\end{array}$ & $\begin{array}{l}\text { Compared to the } \\
\text { control group, } \\
\text { supplementation } \\
\text { groups had higher } \\
\text { peak torque post } \\
\text { training for all } \\
\text { muscles assessed, } \\
\text { and bigger } \\
\text { improvement } \\
\text { post training in } \\
\text { the chair-rising } \\
\text { test (p<0.05). No } \\
\text { difference was } \\
\text { observed between } \\
\text { two intervention } \\
\text { groups ( } 90 \text { versus } \\
150 \text { days). }\end{array}$ & $\begin{array}{l}\text { Fish oil supplementation did } \\
\text { not result in any change in body } \\
\text { mass. Small sample size. }\end{array}$ \\
\hline $\begin{array}{c}\text { Dunn- } \\
\text { Lewis } 2011 \\
\text { [44] }\end{array}$ & $\begin{array}{l}\text { Balanced, } \\
\text { randomized, } \\
\text { double-blind, } \\
\text { placebo- } \\
\text { controlled, } \\
\text { cross-over } \\
\text { trial (at least } \\
\text { 1-wk washout } \\
\text { break) }\end{array}$ & $\begin{array}{c}\text { To examine } \\
\text { the effect of a } \\
\text { multi-nutrient } \\
\text { supplement } \\
\text { (BioCharge } ® \text { ) } \\
\text { on inflammatory } \\
\text { status, joint health } \\
\text { and physical } \\
\text { performance during } \\
\text { the recovery period } \\
\text { of active individuals } \\
\text { age } 40-70 \text { years. }\end{array}$ & $\begin{array}{c}28 \text { days/ } \\
\text { supplementation } \\
\text { period, at least } \\
1 \text { week washout } \\
\text { between periods: } \\
\text { Intervention: } \\
\text { BioCharge }{ }^{\circledR} \\
\text { containing branched } \\
\text { chain amino } \\
\text { acids (taurine, } \\
\text { L-leucine, } \\
\text { isoleucine, valine), } \\
\text { anti-inflammatory } \\
\text { plant extracts (cat's } \\
\text { claw, quercetin, } \\
\text { green tea, biovin } \\
\text { grape extract), } \\
\text { and B vitamins } \\
\text { (B12, B6, folic acid, } \\
\text { pantothenic acid) } \\
\text {-Placebo }\end{array}$ & $\begin{array}{c}\text { Physical } \\
\text { performance, } \\
\text { muscle function, } \\
\text { handgrip strength, } \\
\text { biochemical tests } \\
\text { (i.e. CRP, IL-6), flow } \\
\text { mediated dilation } \\
\text { (FMD) }\end{array}$ & $\begin{array}{c}\text { Healthy and } \\
\text { recreationally } \\
\text { active middle- } \\
\text { aged adults } \\
\text { (mean age: } 56.0 \\
\text { year) } \\
\text { Storrs CT }\end{array}$ & $\mathrm{N}=31$ & 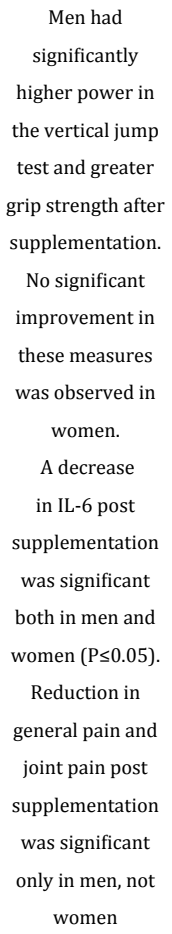 & $\begin{array}{l}\text { No improvement in other } \\
\text { measures such as CRP and FMD } \\
\text { was observed. Anxiety decreased } \\
\text { in women after supplementation. }\end{array}$ \\
\hline
\end{tabular}




\begin{tabular}{|c|c|c|c|c|c|c|c|c|}
\hline $\begin{array}{c}\text { Fuller } 2011 \\
\text { [33] }\end{array}$ & $\begin{array}{c}\text { Randomized, } \\
\text { double-blind, } \\
\text { controlled } \\
\text { trial (placebo } \\
\text { versus } \\
\text { intervention) }\end{array}$ & $\begin{array}{c}\text { To determine } \\
\text { if effects of a } \\
\text { combination } \\
\text { of } \beta \text {-hydroxy- } \\
\beta \text {-methylbutyrate, } \\
\text { arginine, and lysine } \\
\text { (HMB/ARG/LYS) } \\
\text { on muscle strength } \\
\text { were modified by } \\
\text { vitamin D status } \\
\text { [<30 or } \geq 30 \mathrm{ng} / \mathrm{ml} \\
\text { serum } 25(\mathrm{OH}) \mathrm{D}]\end{array}$ & $\begin{array}{c}1 \text { year (taken } \\
\text { with breakfast): } \\
\text { Intervention: daily } \\
\text { supplementation of } \\
\text { HMB/ARG/ } \\
\text { LYS (2.0g CaHMB, } \\
5.0 \mathrm{~g} \text { arginine, and } \\
1.5 \mathrm{~g} \text { lysine) } \\
\text { Control: a drink } \\
\text { consisting of } \\
\text { a mixture of } \\
\text { nonessential amino } \\
\text { acids (5.6g alanine, } \\
0.9 \mathrm{~g} \text { glutamic acid, } \\
3.1 \mathrm{~g} \text { glycine, } \\
2.2 \mathrm{~g} \text { serine) }\end{array}$ & $\begin{array}{l}\text { Total leg muscle } \\
\text { strength (by } \\
\text { the sum of knee } \\
\text { extension and } \\
\text { flexion), body } \\
\text { composition (by } \\
\text { Bioelectrical } \\
\text { Impedance } \\
\text { Analyzer, BIA) }\end{array}$ & $\begin{array}{l}\text { Elderly (mean } \\
\text { age: } 76 \text { years) } \\
\text { Central Iowa, } \\
\text { Iowa }\end{array}$ & $\begin{array}{c}\mathrm{N}=77 \\
\text { Control: } \mathrm{n}=37 \\
-25(\mathrm{OH}) \mathrm{D}<30 \mathrm{ng} / \\
\mathrm{ml}: \mathrm{n}=29 \\
-25(\mathrm{OH}) \mathrm{D} \geq 30 \mathrm{ng} / \\
\mathrm{ml}: \mathrm{n}=11 \\
\\
\text { HMB/ARG/LYS } \\
\mathrm{n}=40 \\
-25(\mathrm{OH}) \mathrm{D}<30 \mathrm{ng} / \\
\mathrm{ml}: \mathrm{n}=25 \\
-25(\mathrm{OH}) \mathrm{D} \geq 30 \mathrm{ng} / \\
\mathrm{ml}: \mathrm{n}=12\end{array}$ & $\begin{array}{c}\text { HMB/ARG/LYS } \\
\text { supplementation } \\
\text { increased FFM } \\
\text { compared to } \\
\text { controls regardless } \\
\text { of vitamin D status. } \\
\text { The HMB/ARG/ } \\
\text { LYS group with an } \\
\text { average of serum } \\
250 H D \geq 30 \mathrm{ng} / \\
\text { ml had significant } \\
\text { strength gains over } \\
\text { the yearlong study } \\
\text { compared to the } \\
\text { other three groups } \\
\text { (p<0.05). }\end{array}$ & $\begin{array}{c}\text { It was a post hoc data analysis } \\
\text { based on serum } 25(\mathrm{OH}) \mathrm{D} \text {. Serum } \\
\text { 25(OH)D was measured at } 0,3,6 \text {, } \\
\text { 9, and } 12 \text { months and an average } \\
\text { value over the yearlong study was } \\
\text { used to stratify vitamin D status } \\
\text {. Two strata by serum } 25(\mathrm{OH}) \\
\text { D within each group: }<30 \text { or } \geq 30 \\
\mathrm{ng} / \mathrm{ml} .\end{array}$ \\
\hline $\begin{array}{c}\text { Smith } 2011 \\
\text { [2] }\end{array}$ & $\begin{array}{c}\text { Randomized, } \\
\text { double-blind } \\
\text { placebo- } \\
\text { controlled } \\
\text { trial (placebo } \\
\text { versus } \\
\text { intervention) }\end{array}$ & $\begin{array}{l}\text { To examine the } \\
\text { effects of omega-3 } \\
\text { fatty acids on the } \\
\text { rate of muscle } \\
\text { protein synthesis } \\
\text { using stable- } \\
\text { isotope-labeled } \\
\text { tracers }\end{array}$ & $\begin{array}{c}8 \text { weeks, } \\
\text { Intervention: omega } \\
3 \text { supplement } \\
\text { (Lovaza, } \\
\text { GlaxoSmithKline) } \\
\text { providing a daily } \\
\text { intake of } 1.86 \mathrm{~g} \\
\text { EPA + } 1.50 \mathrm{~g} \text { DHA } \\
\text { Placebo: identical } \\
\text { looking pills } \\
\text { containing corn oil }\end{array}$ & $\begin{array}{c}\text { At baseline } \\
\text { and } 8 \text { weeks of } \\
\text { intervention: } \\
\text { Basal rate of } \\
\text { muscle protein } \\
\text { synthesis (plasma } \\
\text { phenylalanine } \\
\text { and muscle free } \\
\text { phenylalanine } \\
\text { labeling as } \\
\text { precursor pool } \\
\text { enrichment), } \\
\text { anabolic response } \\
\text { to amino acid and } \\
\text { insulin infusion }\end{array}$ & $\begin{array}{c}\text { Healthy older } \\
\text { adults aged } \geq 65 \\
\text { years } \\
\text { St } \\
\text { Louis, MO }\end{array}$ & $\begin{array}{c}\mathrm{N}=15 \\
\text { Placebo: } \mathrm{n}=7 \\
\text { Intervention: } \mathrm{n}=8\end{array}$ & $\begin{array}{l}\text { Omega-3 fatty } \\
\text { acids doubled the } \\
\text { muscle anabolic } \\
\text { response to amino } \\
\text { acids and insulin } \\
\text { infusion compared } \\
\text { to basal values } \\
\text { (P } \leq 0.01 \text { ). The } \\
\text { increased response } \\
\text { was significantly } \\
\text { different from the } \\
\text { placebo group } \\
\text { (P<0.05). No } \\
\text { effect on the basal } \\
\text { muscle protein } \\
\text { synthesis rate was } \\
\text { observed for both } \\
\text { groups. }\end{array}$ & $\begin{array}{l}\text { No beneficial effects of omega-3 } \\
\text { fatty acids on inflammatory } \\
\text { markers were observed probably } \\
\text { due to low inflammatory status } \\
\text { among these healthy subjects. }\end{array}$ \\
\hline
\end{tabular}




\begin{tabular}{|c|c|c|c|c|c|c|c|c|}
\hline $\begin{array}{c}\text { Zhu } 2010 \\
\text { [29] }\end{array}$ & $\begin{array}{l}\text { Randomized, } \\
\text { double-blind } \\
\text { placebo- } \\
\text { controlled } \\
\text { trial (placebo } \\
\text { versus } \\
\text { intervention) }\end{array}$ & $\begin{array}{l}\text { To examine effects } \\
\text { of vitamin } \mathrm{D}_{2} \text { on } \\
\text { muscle strength } \\
\text { and mobility in } \\
\text { elderly women } \\
\text { with vitamin } \\
\text { D insufficiency } \\
\text { [25(OH)D }<24 \\
\mathrm{ng} / \mathrm{ml}]\end{array}$ & $\begin{array}{c}1 \text { year: } \\
\text { Vitamin D2+caclium } \\
\text { group: } 1000 \mathrm{IU} \\
\text { D2 + } 1000 \mathrm{mg} \\
\text { calcium citrate daily } \\
\text { Placebo (calcium } \\
\text { only) group: } \\
\text { placebo + } 1000 \mathrm{mg} \\
\text { calcium citrate daily }\end{array}$ & $\begin{array}{l}\text { At baseline and } 12 \\
\text { months: Mobility } \\
\text { (TUG), muscle } \\
\text { strength (ankle } \\
\text { dorsiflexion, knee/ } \\
\text { hip flexor, extensor } \\
\text { and abductor } \\
\text { strength), serum } \\
\text { 25(OH)D }\end{array}$ & $\begin{array}{c}\text { Community- } \\
\text { dwelling elderly } \\
\text { women aged } \\
70-90 \text { years } \\
\text { with vitamin } \\
\text { D insufficiency } \\
{[25(\mathrm{OH}) \mathrm{D}<24} \\
\mathrm{ng} / \mathrm{ml}] \\
\text { Perth, Australia }\end{array}$ & $\begin{array}{c}\mathrm{N}=261 \\
\text { Ca: } \mathrm{n}=132 \\
\text { D2+Ca: } \mathrm{n}=129\end{array}$ & $\begin{array}{l}\text { In both groups, } \\
\text { significant } \\
\text { improvement } \\
\text { in knee flexor } \\
\text { strength and } \\
\text { all hip muscle } \\
\text { strength and } \\
\text { mobility (TUG test) } \\
\text { was observed. } \\
\text { But there was no } \\
\text { difference between } \\
\text { groups. After } \\
\text { stratification by } \\
\text { baseline values } \\
\text { of functional } \\
\text { measures, those in } \\
\text { the lowest tertile } \\
\text { had significant } \\
\text { improvement } \\
\text { in hip extensor } \\
\text { (22.6\%), adductor } \\
\text { strength (13.5\%) } \\
\text { and mobility } \\
\text { (17.5\% faster } \\
\text { on TUG test) } \\
\text { at } 12 \text { months } \\
\text { after vitamin D } \\
\text { supplementation } \\
\text { compared to } \\
\text { placebos (P<0.05). }\end{array}$ & $\begin{array}{c}\text { Mean } 25(\mathrm{OH}) \mathrm{D} \text { at baseline: } \\
17.7 \pm 4.2 \mathrm{ng} / \mathrm{ml} \text {. No difference } \\
\text { between groups. At } 12 \text { months, } \\
\text { vitamin D group had significantly } \\
\text { increased vitamin D status } \\
\text { compared to placebos }(79 \% \text { of } \\
\text { subjects had } 25(\mathrm{OH}) \mathrm{D}>20 \mathrm{ng} / \mathrm{ml}) \text {. }\end{array}$ \\
\hline $\begin{array}{c}\text { Cornish } \\
2009 \text { [36] }\end{array}$ & $\begin{array}{c}\text { Randomized, } \\
\text { double-blind } \\
\text { placebo- } \\
\text { controlled } \\
\text { trial (placebo } \\
\text { versus } \\
\text { intervention) }\end{array}$ & $\begin{array}{l}\text { To assess the } \\
\text { effect of } \alpha \text {-linolenic } \\
\text { acid (ALA) } \\
\text { supplementation } \\
\text { on muscle mass, } \\
\text { strength and } \\
\text { inflammation } \\
\text { in older adults } \\
\text { completing a } \\
\text { resistance training } \\
\text { program. }\end{array}$ & $\begin{array}{c}12 \text { weeks with } \\
\text { a resistance } \\
\text { training program } \\
\text { (3 days/week): } \\
\text { Intervention: } \\
30 \mathrm{ml} \text { flax oil/day } \\
\text { ( } \sim 14 \mathrm{~g} \mathrm{ALA} / \text { day) } \\
\text { Placebo: } 30 \mathrm{ml} \text { corn } \\
\text { oil/day }\end{array}$ & $\begin{array}{l}\text { At baseline and } 12 \\
\text { weeks: Muscle } \\
\text { thickness of knee } \\
\text { \& elbow flexors } \\
\text { and extensors } \\
\text { (by ultrasound), } \\
\text { strength (1 } \\
\text { repetition maximum } \\
\text { chest and leg press } \\
\text { strength), body } \\
\text { composition (by } \\
\text { DXA), markers } \\
\text { of inflammation } \\
\text { (TNF- } \alpha, \text { IL-6) }\end{array}$ & $\begin{array}{c}\text { Healthy older } \\
\text { adults aged }>60 \\
\text { years (mean } \\
\text { age: } 65.4 \text { years). } \\
\text { Canada }\end{array}$ & $\begin{array}{c}\mathrm{N}=51 \\
\text { Placebo: } \mathrm{n}=26 \\
\text { ALA: } \mathrm{n}=25\end{array}$ & $\begin{array}{l}\text { The addition of } \\
\text { ALA only lowered } \\
\text { IL-6 levels and } \\
\text { increased knee } \\
\text { flexor muscle } \\
\text { thickness in older } \\
\text { men but not } \\
\text { women. No other } \\
\text { benefits of ALA } \\
\text { were observed. } \\
\text { Progressive } \\
\text { resistance } \\
\text { training increased } \\
\text { muscle thickness, } \\
\text { strength, and lean } \\
\text { tissue mass in } \\
\text { older adults. }\end{array}$ & $\begin{array}{l}\text { Subjects in two groups were } \\
\text { matched for gender. ALA and } \\
\text { placebo oil were comparable } \\
\text { in terms of color and calories. } \\
\text { Compliance rate based on } \\
\text { returned portions of oil: } 78.2 \\
\pm 21.0 \% \text { for placebos vs } 83.6 \pm \\
14.4 \% \text { for ALA group Typical } \\
\text { dietary intake was assessed by a } \\
\text { food frequency questionnaire. } \\
\text { The } \Omega-6 \text { to } \Omega-3 \text { ratio for } \\
\text { the combined dietary and } \\
\text { supplementation sources was } \\
\text { assessed. The ratio decreased } \\
\text { from } 11.6 \pm 0.9 \text { to } 2.3 \pm 0.8 \\
\text { in the ALA group while the } \\
\text { ratio increased in placebos } \\
\text { (11.0 } \pm 0.9 \text { to } 15.9 \pm 0.7 \text { ) over time } \\
\text { (p<0.0001). }\end{array}$ \\
\hline & & & & & & & & $\begin{array}{l}\text { Null effects might be due to a } \\
\text { small sample size. }\end{array}$ \\
\hline
\end{tabular}




\begin{tabular}{|c|c|c|c|c|c|c|c|c|}
\hline $\begin{array}{l}\text { Moreira- } \\
\text { Pfrimer } \\
2009[32]\end{array}$ & $\begin{array}{l}\text { Randomized, } \\
\text { double-blind, } \\
\text { placebo- } \\
\text { controlled } \\
\text { trial (placebo } \\
\text { versus } \\
\text { intervention) }\end{array}$ & $\begin{array}{l}\text { To investigate the } \\
\text { effects of a 6-month } \\
\text { supplementation } \\
\text { with calcium and } \\
\mathrm{D}_{3} \text { on biochemical } \\
\text { parameters and } \\
\text { muscle strength of } \\
\text { institutionalized } \\
\text { elderly. }\end{array}$ & $\begin{array}{c}6 \text { month: } \\
\text { Intervention: daily } \\
\text { calcium (1000 mg) } \\
\text { + monthly } \mathrm{D}_{3} \text { drop } \\
\text { (150,000 IU once } \\
\text { a month during } \\
\text { the first } 2 \text { months, } \\
\text { followed by } 90,000 \\
\text { IU once a month for } \\
\text { the last } 4 \\
\text { Months); } \\
\text { Placebo: daily } \\
\text { calcium (1000 mg) } \\
\text { + monthly placebo }\end{array}$ & $\begin{array}{l}\text { At baseline and the } \\
\text { end of the study } \\
\text { Muscle strength (by } \\
\text { hip flexor and knee } \\
\text { extensors), serum } \\
25(\mathrm{OH}) \mathrm{D}\end{array}$ & $\begin{array}{c}\text { Brazilian } \\
\text { institutionalizing } \\
\text { people aged } \geq 60 \\
\text { years. } \\
\text { Sao Paulo, Brazil }\end{array}$ & $\begin{array}{c}\mathrm{N}=41 \\
\text { Placebo: } \mathrm{n}=25 \\
\text { Intervention: } \\
\mathrm{n}=26\end{array}$ & $\begin{array}{c}\text { Supplementation } \\
\text { of vitamin D } \\
\text { increased serum } \\
\text { 25(OH)D levels } \\
\text { by } 84 \% \text { compared } \\
\text { to baseline values } \\
\text { (vs } 33 \% \text { increase } \\
\text { in placebos due } \\
\text { to seasonality). } \\
\text { Muscle strength } \\
\text { of hip flexors and } \\
\text { knee extensors } \\
\text { was increased by } \\
\text { 16.4\% and } 24.7 \% \text {, } \\
\text { respectively, } \\
\text { compared to } \\
\text { baseline values } \\
\text { (p<0.01) (versus } \\
\text { no improvement } \\
\text { in the placebo } \\
\text { group, p }>0.1 \text { ). } \\
\text { After stratified } \\
\text { by baseline } \\
\text { vitamin D status, } \\
\text { improvement in } \\
\text { strength of hip } \\
\text { flexors was only } \\
\text { significant among } \\
\text { subjects with low } \\
\text { initial vitamin D } \\
\text { status [25(0H) } \\
\text { D<50 nmol/L, } \\
\text { p 0.01] }\end{array}$ & $\begin{array}{l}\text { Low serum 25(OH)D at baseline: } \\
\text { Mean (range): } 39.5 \text { (20.3-68.8) } \\
\text { nmol/l for placebos; } 45.9 \text { (20.3- } \\
\text { 84.8) nmol/l for intervention } \\
\text { group. No difference between } \\
\text { groups (p>0.1). By the end of the } \\
\text { intervention, no subjects in the } \\
\text { intervention group had serum } \\
\text { 25(OH)D levels below } 50 \text { nmol/L, } \\
\text { while } 40 \% \text { of the placebo group } \\
\text { had insufficient vitamin D levels } \\
\quad(<50 \mathrm{nmol} / \mathrm{l})\end{array}$ \\
\hline $\begin{array}{l}\text { Holm } 2008 \\
\qquad[27]\end{array}$ & $\begin{array}{c}\text { Randomized, } \\
\text { double-blind, } \\
\text { placebo- } \\
\text { controlled } \\
\text { trial (placebo } \\
\text { versus } \\
\text { intervention) }\end{array}$ & $\begin{array}{c}\text { To evaluate } \\
\text { the response of } \\
\text { various muscle and } \\
\text { bone adaptation } \\
\text { parameters } \\
\text { within } 24 \text { wk of } \\
\text { strength training } \\
\text { after ingestion } \\
\text { of a nutrient } \\
\text { supplement or a } \\
\text { placebo }\end{array}$ & $\begin{array}{l}\text { Immediately after } \\
\text { each resistance } \\
\text { training session } \\
\text { daily for } 24 \text { weeks: } \\
\text { Intervention: } \\
\text { nutrient supplement } \\
\text { (730 KJ) comprised } \\
\text { of whey protein (10 } \\
\text { g), carbohydrate } \\
(31 \mathrm{~g}) \text {, fat }(1 \mathrm{~g}), \mathrm{D} \\
(5 \mathrm{\mu g}) \text { ), and calcium } \\
(250 \mathrm{mg}) . \\
\text { Placebo: a placebo } \\
\text { supplement } \\
\text { (102k) containing } \\
\text { carbohydrate }(6 \mathrm{~g}) \\
\text { and calcium }(12 \mathrm{mg})\end{array}$ & $\begin{array}{l}\text { At baseline, } 12 \text { and } \\
24 \text { weeks : } \\
\text { Body composition } \\
\text { (by DXA), muscle } \\
\text { strength (by knee } \\
\text { extensor test), } \\
\text { bone mineral } \\
\text { density, markers } \\
\text { of bone turnover } \\
\text { (serum osteocalcin } \\
\text { and collagen type } \\
\text { I cross-linked } \\
\text { carboxyl terminal } \\
\text { peptide) }\end{array}$ & $\begin{array}{l}\text { Healthy, well- } \\
\text { nourished early } \\
\text { postmenopausal } \\
\text { women (mean } \\
\text { age: } 55 \text { years) }\end{array}$ & $\begin{array}{c}\mathrm{N}=29 \\
\text { Placebo: } \mathrm{n}=16 \\
\text { Intervention: } \mathrm{n}=13\end{array}$ & $\begin{array}{l}\text { The lean body } \\
\text { mass in the } \\
\text { intervention } \\
\text { group increased } \\
\text { significantly } \\
\text { ( }<<0.05 \text { ), while } \\
\text { the body fat } \\
\text { mass remained } \\
\text { unchanged in } \\
\text { both group. } \\
\text { The strength } \\
\text { improvement from } \\
6 \text { to } 24 \text { weeks } \\
\text { was significantly } \\
\text { different between } \\
\text { two groups } \\
\text { (p<0.05): } 9 \pm 3 \% \\
\text { in the intervention } \\
\text { group versus } \\
1 \pm 2 \% \text { in placebos. }\end{array}$ & $\begin{array}{l}\text { All women were on a weight- } \\
\text { maintaining diet for the duration } \\
\text { of the study. Bone mineral } \\
\text { density at the lumbar spine at } \\
24 \text { weeks were significantly } \\
\text { improved at both groups. }\end{array}$ \\
\hline
\end{tabular}


were reported in a trial when supplemented with EAAs, vitamin $\mathrm{D}_{3}$ and Medium-Chain Triglycerides (MCTs), indicating a potential synergistic effect with these ingredients [24]. In this trial, elderly people were supplemented with a combination of EAAs (leucineenriched; $40 \%$ leucine in $3 \mathrm{~g}$ EAAs $)+$ vitamin $\mathrm{D}_{3}$ (800 IU) + MCTs (6 gram) or long-chain triglycerides (LCTs, $6 \mathrm{~g}$ ) daily for 3 months. Participants who received leucine-enriched EAAs $+\mathrm{D}_{3}+\mathrm{MCTs}$ had improved mid-upper arm muscle mass, right-hand grip strength (13.1\% higher), walking speed (12.5\% faster) and peak respiratory flow (28.2\% more) compared to baseline values [24]. These changes were significantly different from the control group who did not receive any supplementation [24]. However, no improvements were observed in the EAAs $+\mathrm{D}_{3}+$ LCTs group [24]. As there was no MCTs-only group in this trial, it is not clear if the observed benefit was due to the combination $\left(E A A s+D_{3}+M C T s\right)$ or MCTs [24].

Whey protein and leucine are known to be stimulators of muscle protein synthesis and a combination of both has been reported to help preserve muscle mass and improve muscle strength among older adults with or without exercise. Supplementation on muscle function and mass without exercise was investigated in a multicenter, randomized, controlled, parallel-group trial. In this study, European elderly ( $\geq 65$ years of age) with mobility limitations received vitamin D (800 IU), whey protein $(20 \mathrm{~g})$ enriched with leucine $(3 \mathrm{~g})$, and a mixture of other micronutrients twice per day for 13 weeks. At the end of week 13, the intervention group had greater improvements in lower-extremity function and appendicular muscle mass as compared to the control group $(\mathrm{P}<0.05)$ [25]. Specifically, the gain in appendicular muscle mass after supplementation was $0.17 \mathrm{~kg}$ ( $\sim 1 \%$ total appendicular muscle mass), which would offset a couple years of muscle mass loss among the elderly aged 70 years above [25]. Protein intakes were also increased from $0.8 \mathrm{~g} / \mathrm{kg} /$ day at baseline to $1.5 \mathrm{~g} / \mathrm{kg} \mathrm{BW} /$ day after supplementation [25]. In a similar trial, whey protein (22 g), EAAs (10.9 g, including leucine $4 \mathrm{~g})$, vitamin $\mathrm{D}_{3}$ (100 IU/day) and minerals were supplemented daily to elderly patients with sarcopenia for 12 weeks. All subjects also participated in regular exercise and received a controlled diet (providing 300IU vitamin $\mathrm{D}_{3}$ per day) through the course of the study. At the end of intervention, the supplemented elderly gained $1.7 \mathrm{~kg}$ FFM, and had significantly improved Relative Skeletal Muscle Mass (RSMM) and muscle strength compared to placebo [11]. Similar benefits on skeletal muscle mass were observed in obese older adults who were on a hypocaloric diet and a resistance training program [26]. These dieting older adults consumed a control product or a supplement containing whey protein $\left(20.7 \mathrm{~g} /\right.$ serving), leucine $(2.8 \mathrm{~g} /$ serving $)$ and vitamin $\mathrm{D}_{3}$ (800 IU/serving) in a timely bolus amount (10 servings/week, 3 times immediately after exercise every week) [26]. After the 13-week intervention, both placebo and intervention groups lost weight and fat mass. However, the intervention group preserved $0.9 \mathrm{~kg}$ of appendicular and leg muscle mass compared to placebo $(p<0.05)$ [26]. These measurable differences in skeletal muscle mass were attributed to higher protein intakes in the supplemented group (mean \pm SD: $1.11 \pm 0.28 \mathrm{~g} / \mathrm{kg}$ BW/ day) than in placebo (mean $\pm \mathrm{SD}: 0.85 \pm 0.24 \mathrm{~g} / \mathrm{kg}$ BW/day) [26]. Daily supplementation immediately following resistance training was further investigated among healthy, early postmenopausal women [27]. At the end of 24-week intervention, supplemented subjects ( $10 \mathrm{~g}$ whey protein, $31 \mathrm{~g}$ carbohydrate, 5 $\mu \mathrm{g}$ vitamin $\mathrm{D}$, and $250 \mathrm{mg}$ calcium) had significant improvements in muscle strength and lean body mass compared to placebo $(6 \mathrm{~g}$ carbohydrate +12 mg calcium) $(p<0.05)$ [27]. These data suggest temporal additive benefits of nutrient supplementation when given immediately post exercise.

\section{Vitamin D}

The efficacy of vitamin D on physical functioning and muscle strength has been reported to vary by baseline status, dosage and dosing frequency. A single mega dose of vitamin D (300,000 IU) administered orally and muscularly was reported to improve physical functioning among the elderly 4 weeks after administration [28]. In another trial, vitamin $\mathrm{D}_{2}$ (1,000 IU/day) was given to elderly women with serum 25 -hydroxy vitamin $\mathrm{D}$ [25(OH)D] $<24 \mathrm{ng} / \mathrm{ml}$ for 12 months [29]. Both the intervention and control (calcium only) groups received $1,000 \mathrm{mg} /$ day of calcium throughout the study [29]. Only among those in the lowest tertile of functional measures at baseline did vitamin $\mathrm{D}_{2}$ supplementation improve muscle strength and mobility at 12 months compared to the calcium only group [29]. Specifically, supplementation of vitamin $\mathrm{D}_{2}$ improved Timed Up And Go (TUG) time by $17.5 \%$ in subjects with baseline TUG time $>12$ seconds (the clinical cutoff point for normal mobility), hip extensor strength by $22.6 \%$ and adductor strength by $13.5 \%$ among those with the lowest tertile of baseline values $(\mathrm{P}<0.05)$ [29]. A systematic review of 12 trials reported vitamin $D$ supplementation at a daily dose of $\geq 800$ IU without any exercise improved balance and muscle strength among older adults aged $60+$ years $(\mathrm{P}<0.05)$, though the magnitude of benefit was small [30]. Other dose intervals (i.e. a single dose, weekly, monthly) did not consistently improve these outcomes as daily doses, indicating the relevance of dosing frequency to efficacy [30]. Another recent systematic review of 30 RCTs confirmed positive effects of vitamin $D_{3}$ daily supplementation ( $\geq 400 \mathrm{IU}$ ) on muscle strength ( $17 \%$ increase, $\mathrm{p}<0.05$ ) [31]. Supplementation was reported to be more effective in improving muscle strength among high-risk groups such as those aged $\geq 65$ years or with vitamin D insufficiency [31, 32].

Supplementation of vitamin $\mathrm{D}_{3}$ together with other nutrients (i.e. whey protein, EAAs) has been reported to improve muscle mass, strength and function in a number of trials that were previously described [11, 24-26]. Another trial reported a potential synergy between vitamin $\mathrm{D}$ sufficiency and a cocktail supplementation of $\beta$-hydroxy- $\beta$-methylbutyrate, arginine, and lysine (HMB/ARG/LYS; 2.0g CaHMB, 5.0g arginine, and 1.5 g lysine) on muscle strength. In this trial, supplementation of HMB/ARG/LYS for one year was reported to increase FFM among the elderly compared to the control group regardless of serum $25(\mathrm{OH}) \mathrm{D}$ status [33]. However, significant strength gains at the 
end of 12 months ( $21 \%$ net gain in total leg muscle strength) were observed among supplemented participants with an average of serum $25(\mathrm{OH}) \mathrm{D} \geq 30 \mathrm{ng} / \mathrm{ml}(\mathrm{P}<0.05)$, but not among those with serum $25(\mathrm{OH}) \mathrm{D}<30 \mathrm{ng} / \mathrm{ml}$ [33]. Given elderly adults are at a high risk of vitamin D insufficiency, vitamin D status may be a factor that is worth considering when we design trials or interpret data regarding the efficacy of interventions on functional measures of sarcopenia [33].

Reversed vitamin D insufficiencies with supplementation may contribute to the retention of muscle mass and function [26, 32]. A human study explored vitamin D on muscle metabolism by measuring muscle Fiber Cross-Sectional Area (FCSA) in muscle biopsy tissues from mobility-limited postmenopausal women. Vitamin $\mathrm{D}_{3}$ supplementation (4,000 IU/day) increased total muscle fiber size (type I and II) by $10 \%$ over the 4-month intervention [34]. In a subset of subjects ( $n=14)$, intramyonuclear concentration of vitamin D receptor (VDR) increased by $30 \%$ in the supplemented group [34]. However, the underlying mechanism for which vitamin D improves muscle mass and function remains unclear.

\section{Bovine Colostrum}

Bovine colostrum is known for its unique nutritional composition which includes EAAs, peptides and bioactive components (eg: immunoglobulins), and it has been reported to reduce upper respiratory tract infection among athletes and increase muscle mass during exercise training [35]. The effects of bovine colostrum on muscle strength and bone resorption were compared to whey protein in older adults aged $\geq 50$ years. These participants were randomized to take either $60 \mathrm{~g}$ of colostrum or whey protein daily during resistance training for 8 weeks [35]. After the 8-week intervention, both groups had increased lean tissue mass, muscle thickness, upper body strength and bone mineral content, with no difference between groups $(\mathrm{P}>0.05)$ [35] However, the colostrum group had a greater increase in lower body strength (leg press test) and reduction in bone resorption than the whey protein group $(\mathrm{P}<0.05)$ [35]. Specifically, leg press strength was increased by $21 \%$ in the colostrum supplemented group (versus $5 \%$ in the whey protein group), which may be clinically relevant to those elderly with mobility limitations due to declines in lower body strength [35]. Further research is needed to investigate long-term benefits of bovine colostrum and the underlying mechanism of action [35].

\section{Omega-3 Fatty Acids}

Omega-3 fatty acids have been reported to have mixed results in improving muscle mass and strength in older adults, which may be due to methodological differences such as dosage, duration of intervention, sample size, exercise status, and population characteristics (i.e. gender, muscle status). Alpha-Linolenic Acid (ALA) is a precursor to other omega-3 fatty acids such as DHA and EPA. Its anti-inflammatory effect on muscle mass and strength has been investigated among in an elderly population (aged $>60$ years) with concomitant resistance training [36]. After 12 weeks of flax oil supplementation ( $14 \mathrm{~g}$ ALA/day), Interleukin 6 (IL6) concentrations (a measure of inflammatory status) decreased significantly from baseline to 12 weeks among elderly men but not women [36]. While resistance training improved muscle thickness, strength and lean body mass in both placebo and ALA groups, the addition of ALA did not confer an additional benefit, with the exception of an increase in knee flexor muscle thickness in male subjects [36]. In contrast, supplementation with fish oil ( $2 \mathrm{~g} /$ day, providing $\sim 0.4 \mathrm{~g}$ EPA and $0.3 \mathrm{~g}$ DHA/day) ) along with strength training for 90 days was reported to improve muscle strength and functioning in elderly women compared to the group receiving strength training only [37]. Another trial further investigated gender differences in the effects of $3 \mathrm{~g}$ fish oil daily for 18 weeks (2.1 g EPA and 0.6 g DHA/day) on muscle functioning of older adults who participated in resistance training twice per week during the study period [38]. Significant improvement was observed only among older women, but not men [38]. These data indicate gender may be a factor that influences the efficacy of omega- 3 fatty acids on muscle strength and functioning, and further exploration is needed to confirm sex-specific effects.

A few trials evaluated the effects of omega-3 fatty acids independently of exercise. A commercial supplement (Lavaza, providing a daily dose of $1.86 \mathrm{~g}$ EPA and $1.50 \mathrm{~g}$ DHA) was consumed by healthy older adults for 6 months. At the end of the intervention, supplemented elderly had significantly improved thigh muscle mass, handgrip strength and average muscle power compared to the placebo group [39]. The benefit of omega-3 fatty acids observed in this trial was estimated to prevent 2-3 years of losses in muscle mass and function with age [39]. However, null effects of omega-3 fatty acids on muscle mass and/or strength were observed in older adults with decreased muscle mass (ratio of appendicular lean mass to squared height [ALM index]: below -1 Standard Deviation [SD] of the population reference value) or frailty $[40,41]$. In these trials, the duration of omega-3 supplementation, alone or together with other nutrients (i.e. vitamin E), varied from 3 to 6 months and the daily dosage ranged from $1.2 \mathrm{~g}(0.72 \mathrm{~g}$ EPA and $0.48 \mathrm{~g} \mathrm{DHA})$ to $1.3 \mathrm{~g}(0.66 \mathrm{~g}$ EPA, 0.44 DHA, $0.20 \mathrm{~g}$ other omega-3) [40,41]. More research is needed to help better understand potential interactions between omega-3 fatty acids and other factors (i.e. muscle status, gender) in order to deliver relevant muscular benefit to the elderly.

While the exact mechanism remains unclear, in vitro and in vivo data suggest omega-3 fatty acids may modulate muscle protein synthesis, breakdown, mitochondrial function and lipid content [39, 2, 42]. A recent human trial examined the effects of omega-3 fatty acids on the muscle protein synthesis rate using stable-isotope-labeled tracers among older adults aged $\geq 65$ years [2]. While there was no observed effect on the basal rate of muscle protein synthesis, supplementation of omega- 3 fatty acids for 8 weeks doubled the muscle anabolic response to amino acid and insulin infusion compared to basal values $(\mathrm{P}<0.001)$, and this increase was significantly greater than the placebo group $(\mathrm{P}<0.05)$ [2]. Furthermore, omega-3 fatty acids were reported to regulate select gene expression profiles of human mitochondrial 
function and muscle growth, which may help explain the anabolic resistance-countering effects of omega-3 [42]. Given that the ratio of omega- 3 to omega- 6 in Western diets is much lower than the ancestral diet, supplementation of omega-3 may help achieve a balanced intake of polyunsaturated fatty acids and combat loss of muscle mass with age via augmenting protein metabolism in human muscle [36, 2, 42].

\section{Anti-Inflammatory Ingredients}

The etiology of sarcopenia is not clear, but one contributing factor is believed to be chronic systemic inflammation [36]. Curcumin is known for its anti-inflammatory properties. However, a limitation for the application of curcumin is its low bioavailability. A commercial supplement, Meriva ${ }^{\circledR}$, adopted a novel phospholipid delivery form of curcumin (Phytosome®10) [29]. This supplement, Meriva ${ }^{\circledR}$, has been investigated for the efficacy on sarcopenia parameters in healthy elderly aged 65+ years. During the 3-month intervention, all subjects received standard care including a balanced diet and exercise [43]. Subjects who took $1 \mathrm{~g}$ curcumin/day (Meriva $\left.{ }^{\circledR}\right)$, alone or in combination with vitamin C, D, isoleucine, and carnitine, had significant improvements in muscle strength (hand grip and weight lifting) and physical performance compared to baseline measures and the control group who received standard care only $(\mathrm{P}<0.05)$ [43] . Furthermore, the Meriva ${ }^{\circledR}$ group reported reduced oxidative stress [43]. Given the multi-faceted impact of inflammation and aging on physical function, a combination of anti-inflammatory ingredients has been investigated. Bio Charge $®$ is a multi-nutrient supplement containing branched chain amino acids (taurine, L-leucine, isoleucine, valine), anti-inflammatory plant extracts (cat's claw, quercetin, green tea, biovin grape extract), and $\mathrm{B}$ vitamins $\left(B_{12}, B_{6}\right.$, folic acid, pantothenic acid)[44]. It was taken orally by healthy and recreationally active individuals aged 40-70 years for 28 days. After supplementation, physical performance, hand grip strength, general and joint pain were improved in men, and IL- 6 was reduced both in men and women compared to pre-supplementation values [44]. These data indicate antiinflammatory ingredients may help manage age-related physical limitations.

\section{Conclusion}

This review provides a summary of the current evidence from human RCTs supporting a beneficial role of select nutrients, supplemented alone or in combination with other ingredients, in improving muscle mass and/or function among the elderly. These nutrients include proteins and EAAs, vitamin D, bovine colostrum, omega- 3 fatty acids, and select anti-inflammatory ingredients (curcumin, combination of multiple compounds). A higher protein intake (>0.8 g/kg BW/day) may help preserve muscle mass but more research is needed to examine the responsiveness to protein supplementation by muscle status. EAAs may be beneficial to muscle health when supplemented with other nutrients, but not alone. Favorable effects of vitamin D on muscle strength and physical functioning may be influenced by factors including, but not limited to, baseline status, dosage and dosing frequency. The improvement on body strength by bovine colostrum may be clinically relevant to mobility limitations among older people but its long-term benefit needs to be further investigated. Omega-3 fatty acids appear to be promising in combating losses of muscle mass and strength with age especially when supplemented with concurrent resistance training. Anti-inflammatory ingredients have been reported to improve physical performance among older adults. In summary, cocktail supplementation of multiple nutrients was reported to be more effective than single nutrient interventions. The underlying mechanisms are not fully understood, but may include stimulation of muscle protein synthesis, modulation of muscle protein metabolism, mitochondrial function and lipid content, and/or reduction of chronic inflammation and oxidative stress.

These trials applied various outcome measures, some of which may not be sensitive indicators of sarcopenia. As an example, the Short Physical Performance Battery (SPPB), a measure of physical function, is a categorical measure with less sensitivity to changes than numerical measures [25]. This highlights a methodological challenge we are facing in nutrition research: How can we identify and choose appropriate indicators that are sensitive to changes in functional outcomes? Additionally, the efficacy of nutritional interventions on the retention of muscle mass and function can be influenced by numerous factors including, but not limited to, dosage, dosage frequency, timing, baseline status, host conditions (i.e. vitamin D sufficiency versus insufficiency, healthy versus sarcopenic), and other concomitant nutrients (i.e. synergy between nutrients). A systems approach integrating multi-faceted interventions may help us better understand the multifactorial etiology of sarcopenia and find effective solutions for muscular conditions that occur with age.

\section{Acknowledgments}

Authors thanked Dr. Igor Bendik for his contribution to the concept of the work.

\section{Author Contributions}

All authors contributed to the concept of the work. HK performed the literature search, reviewed and summarized the data, and drafted the manuscript. SP performed the literature search and reviewed the manuscript. ME and SHM reviewed the manuscript. All authors have read and approved the final manuscript.

\section{Conflicts of Interest}

Dr. Hua Kern is an employee of the Nature's Bounty Co.Drs. Szabolcs Péter and Manfred Eggersdorfer are employees of DSM Nutritional Products. Dr. Susan Hazels Mitmesser was an employee of the Nature's Bounty Co. when the work was performed.

\section{References}

1. World population ageing 1950-2050: Magnitude and speed of population ageing. United Nations. 2015. 
2. Smith GI, Atherton P, Reeds DN, Mohammed BS, Rankin D, Rennie MJ, et al. Dietary omega-3 fatty acid supplementation increases the rate of muscle protein synthesis in older adults: a randomized controlled trial. Am J Clin Nutr. 2011;93(2):402-412. doi: 10.3945/ajcn.110.005611

3. Lo YTC, Wahlqvist ML, Huang YC, et al. Medical costs of a low skeletal muscle mass are modulated by dietary diversity and physical activity in community-dwelling older Taiwanese: a longitudinal study. Int J Behav Nutr Phys Act. 2017;14:31. doi: 10.1186/s12966-017-0487-x

4. Janssen I, Heymsfield SB, Wang ZM, Ross R. Skeletal muscle mass and distribution in 468 men and women aged 18-88 yr. J Appl Physiol (1985). 2000; 89(1): 81-88.

5. Gallagher D, Visser M, DeMeersman RE, et al. Appendicular skeletal muscle mass: effects of age, gender, and ethnicity. J Appl Physiol (1985). 1997;83(1): 229-239.

6. Cruz-Jentoft AJ, Baeyens JP, Bauer JM, et al. Sarcopenia: European consensus on definition and diagnosis: Report of the European Working Group on Sarcopenia in Older People. Age Ageing. 2010;39(4): 412-423. doi: 10.1093/ageing/afq034

7. Fielding RA; Vellas B; Evans WJ, et al. Sarcopenia: an undiagnosed condition in older adults. current consensus definition: prevalence, etiology, and consequences. International Working Group on Sarcopenia. J Am Med Dir Assoc. 2011;12(4):249-256. doi: 10.1016/j. jamda.2011.01.003

8. Studenski SA, Peters KW, Alley DE, et al. The FNIH sarcopenia project: rationale, study description, conference recommendations, and final estimates. J Gerontol A Biol Sci Med Sci. 2014;69(5):547-558. doi: 10.1093/gerona/glu010

9. Stewart LK, Flynn MG, Campbell WW, et al. The influence of exercise training on inflammatory cytokines and C-reactive protein. Med Sci Sports Exerc. 2007;39:1714-1719.

10. Latham NK, Bennett DA, Stretton CM, Anderson CS. Systematic review of progressive resistance strength training in older adults. J Gerontol A Biol Sci Med Sci. 2004; 59(1): 48-61.

11. Cruz-Jentoft AJ, Landi F, Schneider SM, et al. Prevalence of and interventions for sarcopenia in ageing adults: a systematic review. Report of the International Sarcopenia Initiative (EWGSOP and IWGS). Age Ageing. 2014;43(6): 748-759. doi: 10.1093/ageing/afu115

12. Rondanelli M, Klersy C, Terracol G, et al. Whey protein, amino acids, and vitamin $\mathrm{D}$ supplementation with physical activity increases fatfree mass and strength, functionality, and quality of life and decreases inflammation in sarcopenic elderly. Am J Clin Nutr. 2016; 103(3): 830840. doi: $10.3945 /$ ajcn.115.113357

13. Kuczmarski MF, Mason MA, Beydoun MA, et al. Dietary patterns and sarcopenia in an urban African American and white population in the United States. J Nutr Gerontol Geriatr. 2013;32(4):291-316. doi: 10.1080/21551197.2013.840255

14. Cardon-Thomas DK, Riviere T, Tieges Z, Greig CA. Dietary protein in older adults: adequate daily intake but potential for improved distribution. Nutrients. 2017;9(3):184. doi: 10.3390/nu9030184

15. Chan R, Leung J, Woo J. A prospective cohort study to examine the association between dietary patterns and sarcopenia in Chinese community-dwelling older people in Hong Kong. J Am Med Dir Assoc. 2016;17(4): 336-342. doi: 10.1016/j.jamda.2015.12.004
16. McClure R, Villani A. Mediterranean diet attenuates risk of frailty and sarcopenia: New insights and future directions. Journal of Cachexia, Sarcopenia and Muscle-Clinical Reports. 2017;2(2):e00045.

17. Mohseni R, Aliakbar S, Abdollahi A, et al. Relationship between major dietary patterns and sarcopenia among menopausal women. Aging Clin Exp Res. 2017:29(6): 1241-1248. doi: 10.1007/s40520-0160721-4

18. Hashemi R, Motlagh AD, Heshmat R, et al. Diet and its relationship to sarcopenia in community dwelling Iranian elderly: a cross-sectional study. Nutrition. 2015;31(1): 97-104. doi: 10.1016/j.nut.2014.05.003

19. Bauer J, Biolo G, Cederholm T, et al. Evidence-based recommendations for optimal dietary protein intake in older people: a position paper from the PROT-AGE study group. J Am Med Dir Assoc. 2013;14(8):542559. doi: 10.1016/j.jamda.2013.05.021

20. Cermak NM, Res PT, de Groot LC, Saris WH, van Loon LJ. Protein supplementation augments the adaptive response of skeletal muscle to resistance-type exercise training: a meta-analysis. Am J Clin Nutr. 2012; 96(6): 1454-1464. doi: 10.3945/ajcn.112.037556

21. Alemán-Mateo H, Carreón VR, Macías L, et al. Nutrient-rich dairy proteins improve appendicular skeletal muscle mass and physical performance, and attenuate the loss of muscle strength in older men and women subjects: a single-blind randomized clinical trial. Clin Interv Aging. 2014;9. 1517-1525. doi: 10.2147/CIA.S67449

22. Alemán-Mateo H, Macías L, Esparza-Romero J, Astiazaran-García H, Blancas AL. Physiological effects beyond the significant gain in muscle mass in sarcopenic elderly men: evidence from a randomized clinical trial using a protein-rich food. Clin Interv Aging. 2012; 7:225-234. doi: 10.2147/CIA.S32356

23. Kim HK, Suzuki T, Saito K, et al. Effects of exercise and amino acid supplementation on body composition and physical function in community-dwelling elderly Japanese sarcopenic women: a randomized controlled trial. J Am Geriatr Soc. 2012; 60(1):16-23. doi: 10.1111/j.1532-5415.2011.03776.x

24. Abe S, Ezaki O, Suzuki M. Medium-chain triglycerides in combination with leucine and vitamin D increase muscle strength and function in frail elderly adults in a randomized controlled trial. J Nutr. 2016;146(5): 1017-1026. doi: 10.3945/jn.115.228965

25. Bauer JM, Verlaan S, Bautmans I, et al. Effects of a vitamin D and leucine-enriched whey protein nutritional supplement on measures of sarcopenia in older adults, the PROVIDE Study: a randomized, doubleblind, placebo-controlled trial. J Am Med Dir Assoc. 2015;16(9):740747. doi: 10.1016/j.jamda.2015.05.021

26. Verreijen AM, Verlaan S, Engberink MF, et al. A high whey protein-, leucine-, and vitamin D-enriched supplement preserves muscle mass during intentional weight loss in obese older adults: a double-blind randomized controlled trial. Am J Clin Nutr. 2015;101(2): 279-286. doi: 10.3945/ajcn.114.090290

27. Holm L, Olesen JL, Matsumoto K, et al. Protein-containing nutrient supplementation following strength training enhances the effect on muscle mass, strength, and bone formation in postmenopausal women. J Appl Physiol (1985). 2008;105(1): 274-281. doi: 10.1152/ japplphysiol.00935.2007

28. Sakalli H, Arslan D, Yucel AE. The effect of oral and parenteral vitamin D supplementation in the elderly: a prospective, double-blinded, 
randomized, placebo-controlled study. Rheumatol Int. 2012;32(8): 2279-2283.

29. Zhu K, Austin N, Devine A, Bruce D, Prince RL. A randomized controlled trial of the effects of vitamin $D$ on muscle strength and mobility in older women with vitamin D insufficiency. J Am Geriatr Soc. 2010;58(11): 2063-2068. doi: 10.1111/j.1532-5415.2010.03142.x

30. Muir SW, Montero-Odasso M. Effect of vitamin D supplementation on muscle strength, gait and balance in older adults: a systematic review and meta-analysis. J Am Geriatr Soc. 2011;59(12): 2291-2300. doi: 10.1111/j.1532-5415.2011.03733.x

31. Beaudart C, Buckinx F, Rabenda V, et al. The effects of vitamin D on skeletal muscle strength, muscle mass, and muscle power: a systematic review and meta-analysis of randomized controlled trials. J Clin Endocrinol Metab. 2014;99(11): 4336-4345. doi: 10.1210/ jc. 2014-1742

32. Moreira-Pfrimer LD, Pedrosa MA, Teixeira L, Lazaretti-Castro M. Treatment of vitamin D deficiency increases lower limb muscle strength in institutionalized older people independently of regular physical activity: a randomized double-blind controlled trial. Ann Nutr Metab. 2009;54(4): 291-300. doi: 10.1159/000235874

33. Fuller JC, Baier $S$, lakoll $P$ et al. Vitamin D status affects strength gains in older adults supplemented with a combination of $\beta$-hydroxy- $\beta$ methylbutyrate, arginine, and lysine: a cohort study. JPEN J Parenter Enteral Nutr. 2011;35(6): 757-762. doi: 10.1177/0148607111413903

34. Ceglia L, Niramitmahapanya S, da Silva Morais M, et al. A randomized study on the effect of vitamin D3 supplementation on skeletal muscle morphology and vitamin D receptor concentration in older women. J Clin Endocrinol Metab. 2013; 98(12): E1927-E1935. doi: 10.1210/ jc.2013-2820

35. Duff WR, Chilibeck PD, Rooke JJ, Kaviani M, Krentz JR, Haines DM. The effect of bovine colostrum supplementation in older adults during resistance training. Int J Sport Nutr Exerc Metab. 2014;24(3):276-285. doi: 10.1123/ijsnem.2013-0182
36. Cornish SM, Chilibeck PD. Alpha-linolenic acid supplementation and resistance training in older adults. Appl Physiol Nutr Metab. 2009;34(1): 49-59. doi: 10.1139/H08-136

37. Rodacki CLN, Rodacki ALF, Pereira G, et al. Fish-oil supplementation enhances the effects of strength training in elderly women. Am J Clin Nutr. 2012;95(2): 428-436. doi: 10.3945/ajcn.111.021915

38. Da Boit M, Sibson R, Sivasubramaniam S, et al. Sex differences in the effect of fish-oil supplementation on the adaptive response to resistance exercise training in older people: a randomized controlled trial. Am J Clin Nutr. 2017;105:151-158.

39. Smith GI, Julliand S, Reeds DN, et al. Fish oil-derived n-3 PUFA therapy increases muscle mass and function in healthy older adults. Am J Clin Nutr. 2015;102(1):115-122. doi: 10.3945/ajcn.114.105833

40. Krzyminska-Siemaszko R, Czepulis N, Lewandowicz M, et al. The effect of a 12-week omega-3 supplementation on body composition, muscle strength and physical performance in elderly individuals with decreased muscle mass. Int J Environ Res Public Health. 2015;12(9):10558-10574. doi: 10.3390/ijerph120910558

41. Hutchins-Wiese HL, Kleppinger A, Annis K, et al. The impact of supplemental $n-3$ long chain polyunsaturated fatty acids and dietary antioxidants on physical performance in postmenopausal women. J Nutr Health Aging. 2013;17(1): 76-80. doi: 10.1007/s12603-0120415-3

42. Yoshino J, Smith GI, Kelly SC, et al. Effect of dietary n-3 PUFA supplementation on the muscle transcriptome in older adults. Physiol Rep. 2016;4(11): e12785. doi: 10.14814/phy2.12785

43. Franceschi F, Feregalli B, Togni S, et al. A novel phospholipid delivery system of curcumin (Meriva ${ }^{\circledR}$ ) preserves muscular mass in healthy aging subject. Eur Rev Med Pharmacol Sci. 2016;20(4):762-766.

44. Dunn-Lewis C, Kraemer WJ, Kupchak BR, et al. A multi-nutrient supplement reduced markers of inflammation and improved physical performance in active individuals of middle to older age: a randomized, double-blind, placebo-controlled study. Nutr J. 2011;10:90. doi: $10.1186 / 1475-2891-10-90$ 